\title{
Reflections on the 2013 European School of Internal Medicine
}

\author{
Runye Gan MDCM
}

\section{About the Author}

Runye Gan is a resident (PGY-5) in general internal medicine at McGill University, in Montreal, Quebec. Correspondence may be directed runye.gan@mail.mcgill.ca.

\section{Summary \\ In this article, the author relates some experiences and key learnings from time spent at the European School of Internal Medicine, in Cappadocia, Turkey. \\ Résumé \\ Dans cet article, l'auteur raconte son expérience à l'École européenne de médecine interne (ESIM) à Cappadoce, en Turquie, et nous fait part des connaissances acquises lors de son séjour.}

$\mathrm{F}$ rom the top of the Uchisar Castle, I watched the sunset after the first day of the European School of Internal Medicine (ESIM), in Cappadocia, Turkey. The landscape, with its scattered beige volcanic rocks, deep valleys, and distant sandy hills with sparse vegetation, made me feel as though I were on a different planet. In truth, I was quite a world away, not only in terms of the physical landscape but also in the world of medicine.

"Why did you not do a Doppler when you did the ultrasound of the liver?" one of the German participants asked, as I was presenting the case of a patient who had developed liver failure in pregnancy. The audience had very astutely brought up the possibility of Budd-Chiari syndrome. It was my first hint that Johannes, with whom I became good friends over the week, had a knack for asking difficult questions. He continued, "We always do the Doppler at the same time as the ultrasound, especially when we are suspecting thromboembolic disease."

I was confused. "When you say 'we,' do you mean 'you,' the internist, or the radiologists of the hospital?"

That seemed to confuse him. "What? You mean you don't do ultrasounds of the abdomen?"

So it was that on the first day of ESIM, with 40 other internists in training from 19 countries, that I made a multitude of amazing discoveries. In Europe, some internists did advanced ultrasound that only radiologists do in North America. In Albania, postgraduate trainees were not paid for the duration of their training. In Sweden, general internal medicine no longer exists as a discipline. The most extraordinary discovery for me was that in many countries, including Germany, Switzerland, and Norway, there are no postgraduate training programs, let alone "residents." It put into question all that I understood about how one developed expertise in the vast field of internal medicine. As a result of my clear astonishment, several participants displayed envy of our highly structured, accredited, and well-supervised Canadian residency programs, something I had very much taken for granted. At dinnertimes, it was a frequent topic of conversation, and I was bemused to find myself talking about the Canadian Resident Matching Service (CaRMS) to interested internists in training so far away from home.

My favourite parts of the conference were the clinical case presentations from each country. I marvelled at the myriad of clinical presentations of both common and rare diseases, and I especially loved the heated debates among the participants that occurred during and after the sessions. The differences in the practice of medicine were sometimes striking. In some countries, syncope in the emergency room was an indication for head to pelvic computed tomography scanning. In others, leishmaniasis was a common differential diagnosis for fever. In yet others, one routinely measured the glutamate dehydrogenase (GLDH), a fifth liver enzyme that had previously been quite unknown to me.

At the same time, it became increasingly clear through our animated discussions that the practice of internal medicine had a universal language. So far away from home, it was heartening to hear the familiar discourse about the importance of history taking and physical examination, rational use of investigations, and evidence-based medicine. Despite our divergent backgrounds and training, when we were confronted with a strange case of hypercalcemia or fever in a patient with 
hepatosplenomegaly, our approaches were remarkably concordant. We prided ourselves on our detective skills, our management of complex problems, and our broad knowledge base. We questioned, commented, and sometimes even argued. Through it all, we bonded via our connection in the common language of internists. I had never before participated in such an engaging and stimulating conference - the differences in our backgrounds made our link even more extraordinary.

As the week progressed, other similarities and common challenges emerged. What is the place of general internal medicine in the world? In a sea of subspecialists, how do we gain recognition for our unique skill set and abilities? How do we navigate the complexities of the different health care structures in our country? As we discussed how hospitals in several countries were closing internal medicine beds to make subspecialist wards, I was once again glad to be an internist in Canada, where general internal medicine has been well established and is even now being recognized as a subspecialty. Yet, as one of my Estonian friends pointed out with equanimity, "They'll realize that is not going to work. They need us. Time will be the solution."

As we all gathered around the dinner tables for our last evening together, I felt very close to the friends I had made over the week. We ate, talked about medicine and life, laughed with each other, and made plans to stay in touch. Yes, there were differences in our careers and lives; yet our common commitment to internal medicine had established a firm bond in just one week. I was no longer a world away but close to home, where we understood, appreciated, and respected each other. I was sad to depart.

Back in Canada, I felt keenly the importance of making our place as general internists well established so that we can continue to deliver high-quality care. At my residency training committee meeting, I reflected that I was grateful to have received excellent quality education for the past five years just by virtue of being a "resident." When I got home one day, I received a greeting from far away - Johannes had sent me a wealth of resources on self-directed online learning of ultrasonography. Perhaps one day, I will be performing wholebody ultrasounds in patients in the ICU. It is not such a far-fetched idea. After all, I could never have imagined that I would feel at home in the international community of internists, either, in the foreign landscapes of Turkey.

ESIM 2013 was an unforgettable experience that will accompany me over the next decades. I look forward to regreeting my friends in Europe at an international conference one day. Perhaps I can impress my German colleagues with my ultrasound skills then. One can always hope! 